\title{
The evaluation of preoperative and histopathologic diagnosis in specimens of hysterectomy performed for benign conditions
}

\author{
Ozan Turgut ${ }^{1}$, Serdar Yanık ${ }^{2}$, Aybala Agac Ay ${ }^{3}$, Isin Gencay ${ }^{4}$, Sümeyra Nergiz $^{5}$, Ahmet ${ }^{6}$, \\ Oktay Aydin ${ }^{7}$ \\ ${ }^{1}$ Iskenderun State Hospital, Gynecology Clinic, Hatay, Turkey \\ ${ }^{2}$ Iskenderun State Hospital, Pathology Clinic, Hatay, Turkey \\ ${ }^{3}$ Kirikkale University, School of Medicine, Department of General Surgery, Kirikkale, Turkey \\ ${ }^{4}$ Kirikkale University, School of Medicine, Department of Anesthesiology and Reanimation, Kirikkale, Turkey \\ ${ }^{5}$ Adnan Menderes University, School of Medicine, Department of Gynecology, Aydin, Turkey \\ ${ }^{6}$ Kirikkale Yuksek Ihtisas Hospital, Department of General Surgery, Kirikkale, Turkey \\ ${ }^{7}$ Gaziantep Dr.Ersin Aslan State Hospital, Department of General Surgery, Gaziantep, Turkey
}

\section{Email address:}

draybala.a.a@gmail.com (A. A. Ay)

\section{To cite this article:}

Ozan Turgut, Serdar Yanık, Aybala Agac Ay, Isin Gencay, Sümeyra Nergiz, Ahmet Ay, Oktay Aydin. The Evaluation of Preoperative and Histopathologic Diagnosis in Specimens of Hysterectomy Performed for Benign Conditions. Journal of Surgery.

Vol. 2, No. 1, 2014, pp. 11-13. doi: 10.11648/j.js.20140201.14

\begin{abstract}
The aim of this study is to evaluate hysterectomy procedures performed for benign conditions in terms of indications and histopatho-logical results. Retrospective analysis of 32 hysterectomy cases, which were performed between January 2011 and Decem-ber 2012, was conducted to review indications and histo-pathological diagnoses. The most frequent indications for hysterectomy were abnormal uterine bleeding myoma uteri and endometrial hyperplasia, respectively. Other clinical indications were adenomyosis and uterine prolapse .The most common histopathological diagnoses reported for hysterectomy specimens were leiomyoma adenomyosis and endometrial hyperplasia respecti-vely. Endometrial polyp was diagnosed in specimens of patients. Endometrial atrophy was reported in patients. Cervical histopathology of hysterectomy materials revealed chronic cervicitis in of the patients. Due to the high coincidence of myoma uteri and endometrial hyperplasia, endometrial sampling should be performed in patients who are being considered for hysterectomy.
\end{abstract}

Keywords: Hysterectomy, Benign Diseases, Pathological Evaluation

\section{Introduction}

Hysterectomy is defined as the surgical removal of the uterus. It is one of the most common of all surgical procedures and can also involve the removal of the fallopian tubes, ovaries and cervix to cure or alleviate a number of gynaecological complaints[1]. The most frequent indications for hysterectomy are abnormal uterine bleeding myoma uteri and endometrial hyperplasia. Other clinical indications are adenomyosis and uterine prolapse. The most common histopathological diagnoses reported for hysterectomy specimens were leiomyoma adenomyosis and endometrial hyperplasia [2].

There are three approaches to hysterectomy for benign diseases: abdominal hysterectomy $(\mathrm{AH})$, vaginal hysterectomy ( $\mathrm{VH})$ and laparoscopic hysterectomy ( $\mathrm{LH})$. Laparoscopic hysterectomy has three further subdivisions laparoscopic assisted vaginal hysterectomy $(\mathrm{LAVH})$ where a vaginal hysterectomy is assisted by laparoscopic procedures that do not include uterine artery ligation, laparoscopic hysterectomy (which we will abbreviate to $\mathrm{LH}(\mathrm{a})$ ) where the laparoscopic procedures include uterine artery ligation, and total laparoscopic hysterectomy (TLH) where there is no vaginal component and the vaginal vault is sutured laparoscopically [3].

The aim of this study to evaluate hysterectomy procedures performed for benign conditions in terms of indications and histopathological results. 


\section{Patients and Methods}

Thirty two patients who were operated for beningn caused total abdominal and vaginal hysterectomy between January 2011 and November 2013 were investigated retrospectively. The hysterectomy indications and histopathological examination of the hysterectomy materials were evaluated. Demographical features were noted. The statistical analysis was made with PSPP0.8.1 programme for Windows.

\section{Results}

Total of 32 hysterectomy materials between january 2011 and november 2013 were evaluaed. The age avarage of the patients was $48.18 \pm 5.87$ (39-67). The most common hysterectomy indication was abnormal uterine bleeding which was observed in 24 cases $(75 \%)$. The second indication was uterine myoma in 4 cases $(12.50 \%)$ and endometrial hyperplasia in 2 cases $(6.25 \%)$. Both adenomyosis (6.25\%) and uterine prolapsus (3.13\%) were observed in one patient (Table1).

Table 1. The clinical hysterectomy indications (\%)

\begin{tabular}{lcc}
\hline Indication & Number (n) & Ratio (\%) \\
\hline Abnormal utrine bleeding & 24 & 75.00 \\
Uterine myoma & 4 & 12.50 \\
Endometrial hyperplasia & 2 & 6.25 \\
Adenomyosis & 1 & 3.13 \\
Uterine prolapsus & 1 & 3.13 \\
\hline
\end{tabular}

After the hystopathological examination of the hysterectomy materials the results were as follows; 15 patients were diagnosed as leiomyoma $(46.87 \%), 4$ patient were diagnosed as adenomyosis (12.50\%) and 3 patients were endometrial hyperplasia (9.38\%). Endometrial polyp was observed only in one patient $(3.17 \%)$ and 7 patients had combined pathological disorders $(21.87 \%)$ (Table 2$)$.

Table 2. Types of the hystopathological diagnosis

\begin{tabular}{lcc}
\hline Indication & Number (n) & Ratio (\%) \\
\hline Leiomyoma & 15 & 46.8 \\
Adenomyosis & 4 & 12.5 \\
Endometrial hyperplasia & 3 & 9.38 \\
Endometrial polyp & 1 & 3.13 \\
Leiomyosarcoma & 2 & 6.25 \\
Combined pathology & 7 & 21.87 \\
\hline
\end{tabular}

Combined pathologies were detected in 7 patients. The most common comorbidities were adenomyosis and uterine myoma in 4 cases $(34.57 \%)$. However, uterine myome and endometrial polyp coexistence were less often with 2 cases $(6.25 \%)$. Only in one case the endometrial hyperplasia was seen together with uterine myoma.

The histopathological subtypes of endometrial hyperplasia in 3 patiens were identified as follows; simple endometrial hyperplasia in one patient $(3.13 \%)$, complex atypical hyperplasia in one patient $(3.13 \%)$, complex non atypical hyperplasia in one patient $(3.13 \%)$.

The age avarages with respect to the histopathological diagnosis were, $46.75( \pm 6.55)$ for adenomyosis, 47.33 $( \pm 5.25)$ for uterine myoma, $50.33( \pm 5.50)$ for endometrial hyperplasia and $45.50( \pm 0.70)$ for leiomyosarcoma. Only one patient diagnosed as endometrial polyp was 44 years old Two patients with leiomyosarcoma were underwent surgery for abnormal bleeding.

\section{Discussion}

Leiomyomas, also known as fibroids, are the most frequent benign uterine tumors that develop during a woman's reproductive years; occurrence tends to regress after menopause [4]. Symptoms related to UL are menstrual disorders, mainly menorrhagia, pelvic pain, and infertility, which can adversely affect pregnancy outcomes [4-6]. Approximately, 140.000 hysterectomies and 20.000 myomectomies were applied within one year based on leiomyoma caused symptoms [7].

Isaoglu et al. reported that leiomyoma constituted a significant part of hysterectomy indications (28.19\%)[2]. However Dincgez and friends found that $32.77 \%$ of hysterectomies were diagnosed as uterine myoma[9]. In our study leiomyoma incidence of hysterectomy cases were $6.25 \%$.

Abnormal uterine bleeding (AUB) is a common cause for women in the reproductive age group that consulted to a doctor. AUB is also the common cause for iron deficiency anemia in our country, especially in the reproductive age group. Uterine fibroid, adenomyosis, polyp (endometrial and endocervical), endometrial hyperplasia and malignancy are the structural causes for AUB [10]. Abnormal uterine bleeding was the most common histerectomy indication in our study $(75 \%)$.

Oeda et al. showed that, $44 . \%$ of the hysterectomy cases were leiomyoma, $22.3 \%$ of them were endometrial hyperplasia, $12.23 \%$ were malign disorders and $6.44 \%$ were endometriosis [11]. Another study made by Atılgan and friends, 361 hysterectomy cases were evaluated and $40.16 \%$ were uterine myoma, $38.22 \%$ of the cases were endometrial hyperplasia, $25.48 \%$ were adenomyosis and $8.86 \%$ were endometrial polyp[12]. Isaoglu et al demonstrated that $32.17 \%$ of the cases were leomyma, $30.23 \%$ were adenomyosis, $29.84 \%$ were endometrial hyperplasia and $5.04 \%$ were endometrial polyp [2]. After the examination of the hystopathological material we found that the most common indication was leiomyoma in 15 patients $(46.87 \%)$, the second was adenomyosis in 4 cases (12.50\%) and endometrial hyperplasia in 3 patients $(9.38 \%)$. Endometrial polyp was detected in only one patient (3.13\%) and 7 patients were diagnosed as combined pathologies $(21.87 \%)$. Adenomyosis is an another common condition detected in hysterectomy specimens. It is characterized by the presence of endometrial glands and stroma within the myometrium. Patients are typically pre or perimenopausal women who 
present with abnormal bleeding [10]

Hysterectomy operations applied for benign gynaecological occasoins were reported as $25-35 \%$ (13). Cakmak and friends involve 149 hysterectomy patients in their study and the histopathological examination revaled that adenomyosis incidance was 11.4\% [14]. In fact Isaoglu et al. found that $30.23 \%$ of the hysterectomy cases were diagnosed as adenomyosis [2]. However in our study the adenomyosis was detected in $12.50 \%$ of the patients.

Endometrial hyperplasia has been classified into 3 main subtypes: simple hyperplasia, characterized by minimal endometrial glandular crowding and with low risk of progression to endometrial carcinoma; complex hyperplasia, characterized by greater endometrial glandular crowding and intermediate risk of progression; and atypical hyperplasia, comprised of endometrium with complex glandular crowding and/or cytologic atypia and the greatest risk of endometrial carcinoma progression [15].

Endometrial hyperplasia has been a gyneacological condition that could be seen in women of all age goups and the patients have usually presented with atypical uterine bleeding [2]. In our study endometrial hyperplasia were seen in $9.38 \%$ of the patients.

Combined pathological disorders could also be seen after the hystopathologic examination. Shagill et al. involved 100 hysterectomy cases in their study and histopathological examination revaled that 38 patients were diagnosed as leomyoma together with adenomyosis, 25 cases were only presented with leiomyoma and 3 cases were identified as only adenomyosis[16]. However adenomyosis with uterine myoma were seen in 4 of our cases $(34.57 \%)$, uterine myoma and endometrial polyp coexistance were less often and seen in 2 patients $(6.25 \%)$, endometrial hyperplasia together with uterine myoma was only seen in one patient (3.13\%) respectively.

As a result, we think that despite the clinical diagnosis, hystopathological evaluation of the hysterectomy materials revealed that adenomyosis, endometrial polyp and leiomyosarcoma were much more common pathologies, the existance of sarcomatous transformation should be recognised and prepared for the oncological procedures.

\section{References}

[1] National Collaborating Centre for Women's and Children's Health (UK). Heavy Menstrual Bleeding. London: RCOG Press; 2007 Jan. (NICE Clinical Guidelines, No. 44.) 12, Hysterectomy. Available http://www.ncbi.nlm.nih.gov/books/NBK56535/
[2] Isaoğlu U.The Evaluation of Histopathologic Diagnosis in Specimens of Hysterectomy.Abant Med J. 2013; 2(2):91-943

[3] Surgical approach to hysterectomy for benign gynaecological disease. Nieboer $T$ DOI: $10.1002 / 14651858 . C D 003677 . p u b 3)$

[4] Moutinho JAF,Barbosa LG,Torres DG,Nunes SM. Abnormal uterine bleeding as a presenting symptom is related to multiple uterine leiomyoma: an ultrasound-based study.Int $\mathbf{J}$ Womens Health. 2013; 5: 689-694.

[5] Buttram VC, Jr, Reiter RC. Uterine leiomyoma: etiology, symptomatology and management. Fertil Steril. 1981;36:433-445.

[6] Haney AF. Clinical decision making regarding leiomyomata: what we need in the next millennium. Environ Health Perspect. 2000;108(Suppl 5):835-839.

[7] Lepine LA, Hillis SD, Marchbanks PA, Koonin LM, Mor-row B, Kieke BA, Wilcox LS. Hysterectomy surveillance- United States 1980-1997. MMWR 1997; 46: $1-15$.

[8] Cramer SF, Patel A. The frequency of uterine leiomyo-mas. Am J Clin Pathol 1990; 94: 435-8.

[9] Dinçgez B, Coşkun Eİ, Ayanoğlu YT. Kliniğimizde gerçekleştirilen histerektomi olgularının değerlendirilmesi. Şişli Etfal Hastanesi Tıp Bülteni 2011; 45: 35-8.

[10] Rizvi G,Pandey H,Pant H,Chufal SS,Pant P. Histopathological correlation of adenomyosis and leiomyoma in hysterectomy specimens as the cause of abnormal uterine bleeding in women in different age groups in the Kumaon region: A retroprospective study.J Midlife Health. 2013 Jan-Mar; 4(1): 27-30.

[11] Ojeda VJ. The pathology of hysterectomy specimens. Z Med J 1979; 89: 169-71.

[12] Atılgan R, Boztosun A, Ozercan MR. Histerektomi materyallerinde histopatolojik tanıların insidansı. Firat Tip Dergisi 2012; 17: 19-229.

[13] Kunz G, Beil D, Huppert P, Noe M, Kissler S, Leyen-decker G. Adenomyosis in endometriosis prevalence and impact on fertility. Evidence from magnetic resonance imaging. Hum Reprod 2005; 20: 2309-16.

[14] Çakmak B, Özsoy Z, Hısım Y, Nacar M, Metin FZ, Demirtürk F. Benign endikasyonlar nedeniyle uygulanan histerektomi materyallerinde adenomyozis sıklığı. Çağdaş T1p Dergisi 2012; 2: 158-161.

[15] Reed SD, Newton, KM; Clinton WL, et al. Incidence of endometrial hyperplasia. Am J Obstet Gynecol 2009;200:678.e1-678.e6.

[16] Shegill SK, Shergill HK. Clinicopathological study of hysterectomies. J Indian Med Assoc 2002; 100: 238 